\title{
Morphological and phenotypical features of ovarian metastases in breast cancer patients
}

Inge T. A. Peters ${ }^{1}$, Merle A. van der Steen², Bertine W. Huisman², Carina G. J .M. Hilders' ${ }^{3}$, Vincent T. H. B. M. Smit ${ }^{4}$, Alexander L. Vahrmeijer ${ }^{2}$, Cornelis F. M. Sier ${ }^{2}$, J. Baptist Trimbos $^{1}$ and Peter J. K. Kuppen ${ }^{2^{*}}$

\begin{abstract}
Background: Autotransplantation of frozen-thawed ovarian tissue is a method to preserve ovarian function and fertility in patients undergoing gonadotoxic therapy. In oncology patients, the safety cannot yet be guaranteed, since current tumor detection methods can only exclude the presence of malignant cells in ovarian fragments that are not transplanted. We determined the need for a novel detection method by studying the distribution of tumor cells in ovaries from patients with breast cancer. Furthermore, we examined which cell-surface proteins are suitable as a target for non-invasive tumor-specific imaging of ovarian metastases from invasive breast cancer.

Methods: Using the nationwide database of the Dutch Pathology Registry (PALGA), we identified a cohort of 46 women with primary invasive breast cancer and ovarian metastases. The localization and morphology of ovarian metastases were determined on hematoxylin-and-eosin-stained sections. The following cell-surface markers were immunohistochemically analyzed: E-cadherin, epithelial membrane antigen (EMA), human epidermal growth receptor type 2 (Her2/neu), carcinoembryonic antigen (CEA), avß6 integrin and epithelial cell adhesion molecule (EpCAM).

Results: The majority of ovarian metastases (71\%) consisted of a solitary metastasis or multiple distinct nodules separated by uninvolved ovarian tissue, suggesting that ovarian metastases might be overlooked by the current detection approach. Combining the targets E-cadherin, EMA and Her2/neu resulted in nearly 100\% detection of ductal ovarian metastases, whereas the combination of EMA, Her2/neu and EpCAM was most suitable to detect lobular ovarian metastases.
\end{abstract}

Conclusions: Examination of the actual ovarian transplants is recommended. A combination of targets is most appropriate to detect ovarian metastases by tumor-specific imaging.

Keywords: breast cancer, fertility preservation, ovarian metastases, ovarian tissue autotransplantation, tumor markers, tumor-specific imaging

\section{Background}

Cryopreservation of ovarian tissue is the only option to preserve fertility and restore ovarian activity in prepubescent girls and women who cannot postpone the start of adjuvant chemotherapy [1]. Although autotransplantation of frozen-thawed cortical ovarian tissue has resulted in more than 86 live births worldwide [2], this method has not yet been endorsed by the American

\footnotetext{
* Correspondence: p.j.k.kuppen@lumc.nl

2Department of Surgery, Leiden University Medical Center, Leiden, the Netherlands

Full list of author information is available at the end of the article
}

Society for Reproductive Medicine (ASRM) [3]. One of the reasons that the ASRM committee has put forward is that the safety of the procedure has not been substantiated in patients with cancer. Cortical ovarian tissue may contain malignant cells that could lead to reseeding of cancer upon autotransplantation. This risk of reintroducing malignant cells cannot be eliminated, since the current tumor detection methods (e.g. PCR, immunohistochemistry) jeopardize the ovarian tissue's viability [4]. These methods can therefore only be used to examine cortical ovarian strips that are not transplanted. 
Hence, the presence of tumor cells in the actual ovarian autografts remains questionable.

Whether the current approach for tumor detection is accurate depends on the distribution of metastatic tumor cells in the ovarian tissue [5, 6]. If tumor cells are diffusely dispersed throughout the ovary, examination of one or two cortical ovarian strips might be sufficient. By contrast, if tumor cells are confined to a specific area in the ovarian cortex, this approach is inadequate. Then, cortical ovarian strips that are examined may turn out to be devoid of tumor cells whereas ovarian fragments that harbor metastases may be transplanted, possibly resulting in cancer relapse.

The implementation of a detection method that allows examination of the cortical ovarian strips that will be transplanted, will significantly reduce the risk of transferring malignant cells. Near-infrared fluorescence (NIRF) imaging might be an appropriate approach, as this technique discriminates malignant cells from nonmalignant tissue in real time while leaving the tissues viable [7]. A NIRF probe consists of a fluorophore that emits light in the near-infrared spectrum $(\lambda=700$ $900 \mathrm{~nm}$ ) and an antibody or peptide with high affinity for a protein expressed specifically at the cell surface of tumor cells $[8,9]$.

In order to use tumor-specific imaging to exclude malignant cells in cortical ovarian autografts, tumor markers should be identified that are present at the cell surface of ovarian metastases. Since a substantial proportion of patients who undergo ovarian tissue cryopreservation is diagnosed with breast cancer [10-12], we tested a panel of cell-surface markers known to be expressed by breast cancer cells, including E-cadherin [13], epithelial membrane antigen (EMA, also known as MUC1) [14, 15], human epidermal growth factor receptor type $2(\mathrm{Her} 2 / \mathrm{neu})[16,17]$, carcinoembryonic antigen (CEA) [18], $\alpha v \beta 6$ integrin [19] and epithelial cell adhesion molecule (EpCAM) [20-22]. The markers cytokeratin CAM 5.2, gross cystic disease fluid protein15 (GCDFP15), Wilms' tumor antigen-1 (WT1), mammaglobin 1, and cytokeratin 7 (CK-7), which were used by Sánchez-Serrano et al. [23] and Rosendahl et al. [6], were excluded, as they are not expressed at the cell surface and therefore not suitable as a target for tumorspecific imaging.

In this study, we assessed the distribution of breast tumor cells in ovarian tissues from patients with ovarian metastases and determined which cell-surface proteins are suitable as a target for tumor-specific imaging of ovarian metastases derived from invasive breast cancer. Because it is crucial to select a target prior to the administration of the NIRF probe, we also examined whether invasive breast cancer tissue can be used to predict the most suitable target for the detection of ovarian metastases in a particular patient.

\section{Methods}

\section{Patient selection and tissue collection}

Via a nationwide search performed by PALGA, the Dutch histopathology and cytopathology network that encompasses all pathology laboratories within the Netherlands [24], a source population was compiled. This source population consisted of all patients who were diagnosed with primary invasive breast cancer at age $<41$ years in the period 2000-2010 and who subsequently underwent an oophorectomy for any reason. From this source population, all patients who had histologically confirmed ovarian metastases from primary invasive breast cancer, were selected. Following this, hematoxylin-and-eosin (H\&E) stained tissue sections and formalin-fixed paraffin-embedded (FFPE) tissue samples from the primary invasive breast tumors and their corresponding ovarian metastases were requested from pathology laboratories. If patients had locally recurrent breast cancer or a second primary invasive breast tumor prior to oophorectomy, FFPE tissue samples from these tumors were also requested. Clinical data were extracted from the patient's files after approval by the medical ethical committee of the Leiden University Medical Center (protocol number P14.106) and the local medical ethical committees of the participating hospitals.

\section{Distribution of breast cancer cells in the ovary}

The distribution of breast cancer cells in ovarian tissues was evaluated using the original H\&E-stained sections by assessment of their localization and morphological features. The localization of breast cancer cells was determined as confined to the ovarian cortex and/or medulla. With respect to morphology, breast cancer cells were classified as a solitary metastasis, multiple distinct nodules separated by uninvolved ovarian tissue, or diffuse seeding without any discernable pattern.

\section{Immunohistochemistry}

Immunohistochemistry was performed on $4-\mu \mathrm{m}$ thick FFPE sections of primary invasive breast cancers, locally recurrent breast cancers (if applicable) and their corresponding ovarian metastases. The tissue sections were deparaffinized in xylene, dehydrated in a stepwise series of graded alcohol solutions, and rinsed in distilled water. After blocking endogenous peroxidase activity with $0.3 \%$ hydrogen peroxide for $20 \mathrm{~min}$, heat-induced antigen retrieval was performed by placing the slides in EnVision Flex Target Retrieval Solution high $\mathrm{pH}$ (pH 9.0; Ecadherin, EMA) or in the same solution but low $\mathrm{pH}$ (pH 6.0; Her2/neu) in PT Link (Dako, Denmark). EpCAM and $\alpha v \beta 6$ integrin epitopes were unmasked by 30 -min incubation with $0.125 \%$ trypsin and $0.4 \%$ pepsin, respectively, at $37{ }^{\circ} \mathrm{C}$. For CEA, no antigen retrieval was 
required. The sections were incubated overnight in a humidified chamber at room temperature with primary antibodies against Her2/neu (ERBB2, rabbit polyclonal, Dako), E-cadherin (NCH38, mouse monoclonal, Dako), EpCAM (323/A3, mouse monoclonal, provided by the Department of Pathology, LUMC, the Netherlands), CEA (A0115, rabbit polyclonal, Dako), $\alpha v \beta 6$ integrin (6.2A1, mouse monoclonal, Cell Essentials), or EMA (E29, mouse monoclonal, Dako); all primary antibodies were used at their predetermined optimal dilution. After incubation with primary antibodies, the sections were rinsed with PBS, incubated with secondary antibodies (anti-mouse or anti-rabbit EnVision; Dako) for $30 \mathrm{~min}$, and visualized using liquid $\mathrm{DAB}+$ substrate buffer (Dako). The sections were counterstained with Mayer's hematoxylin solution, dehydrated, and mounted with Pertex (Leica Microsystems, Germany). For each immunostain, tissues expressing the antigen of interest were included as a positive control. Tissue sections stained without application of the primary antibody were used as a negative control.

\section{Immunofluorescent triple staining}

For immunofluorescent triple staining, the three most highly expressed markers for ductal and lobular ovarian metastases were chosen. In brief, FFPE sections of these ovarian metastases were deparaffinized as described above. Antigen retrieval was performed by placing the slides in EnVision Flex Target Retrieval Solution high $\mathrm{pH}$ (pH 9.0; Dako). Primary antibodies for ductal ovarian metastases: E-cadherin, EMA and Her2/neu. Primary antibodies for lobular ovarian metastases: EMA, Her2/neu and EpCAM. Secondary antibodies were all isotype-specific antibodies with Alexa Fluorochromes (LifeTechnologies, USA): anti-mouse IgG1-AlexaFluor488 (E-cadherin and EpCAM; green), anti-mouse IgG2a-AlexaFluor647 (EMA; red) and anti-rabbit-AlexaFluor546 (Her2/neu; orange). Sections were mounted with Vectashield containing DAPI (Vector Laboratories, USA). Primary invasive breast tumor samples that showed positive expression for all markers in previous experiments were used as a positive control. Tissue sections stained without application of primary antibodies were used as a negative control.

\section{Image capture and quantification of immunoreactivity}

The immunohistochemically stained slides were digitized using an IntelliSite Pathology Ultra-Fast Scanner 1.6 RA (Philips, The Netherlands). The percentage of malignant cells with immunohistochemically positive stained membranes were scored by two independent observers (I.P. and M.S.). In case of discrepancy, the observers reached consensus regarding a final score. The tumor cell membranes were considered positive if they showed immunoreactivity of any intensity. The immunofluorescent stained slides were digitized using a Pannoramic MIDI digital slide scanner (3DHistech, Hungary). The percentage of malignant cells with immunofluorescent positive stained membranes were also scored by two independent observers (I.P. and B.H.).

\section{Statistical analysis}

Statistical analysis was performed using SPSS version 23.0 (IBM, Armonk, NY). Inter-observer agreement was calculated using the Pearson correlation coefficient. Scatter plots based on generalized estimating equations analysis were made to determine whether invasive breast cancer tissue can be used to predict the most suitable target for the detection of ovarian metastases in a particular patient.

\section{Results}

Patient selection and clinicopathological characteristics According to the PALGA registry, 2648 patients were diagnosed with primary invasive breast cancer at age $<41$ years in the period 2000-2010 in the Netherlands who subsequently underwent an oophorectomy (Fig. 1). Among these patients, 63 patients had ovarian metastases. Of these 63 patients, tumor tissue samples were available from 46 patients. These 46 patients were included in this study. The clinicopathological characteristics of the $46 \mathrm{pa}-$ tients are shown in Table 1 . The median age at the time of diagnosis was 36.5 years (range $28-40$ years). Thirty-six patients were diagnosed with invasive ductal breast cancer and five patients were diagnosed with invasive lobular breast cancer. The remaining five patients had invasive ductolobular breast cancer. Almost 15\% of patients had distant metastases outside the ovary at the time of breast cancer diagnosis. The median time between this diagnosis and oophorectomy was 41.9 months (range 0.3-141.8 months). In the majority of cases, the oophorectomy was done prophylactically or therapeutically because of breast cancer. In only one fourth of cases, the ovaries were removed because they appeared abnormal on ultrasound. Further patient and tumor characteristics are presented in Table 1.

\section{Localization and morphology of ovarian metastases}

Of the 46 patients, 29 patients had metastases in both ovaries (Table 1). Therefore, the total number of ovaries that contained metastases was 75 . The localization and morphology of these 75 ovarian metastases are shown in Table 2. In 14 ovaries (19\%) the metastases seemed confined to the cortex, whereas in 53 ovaries $(70 \%)$ both the cortex and medulla were involved (Table 2). In half of the ovaries multiple distinct nodules were seen, while in $20 \%$ a solitary metastasis was found. Diffuse seeding without any discernable pattern was observed in $29 \%$ of ovaries. Figure 2 shows examples of these morphological features. 


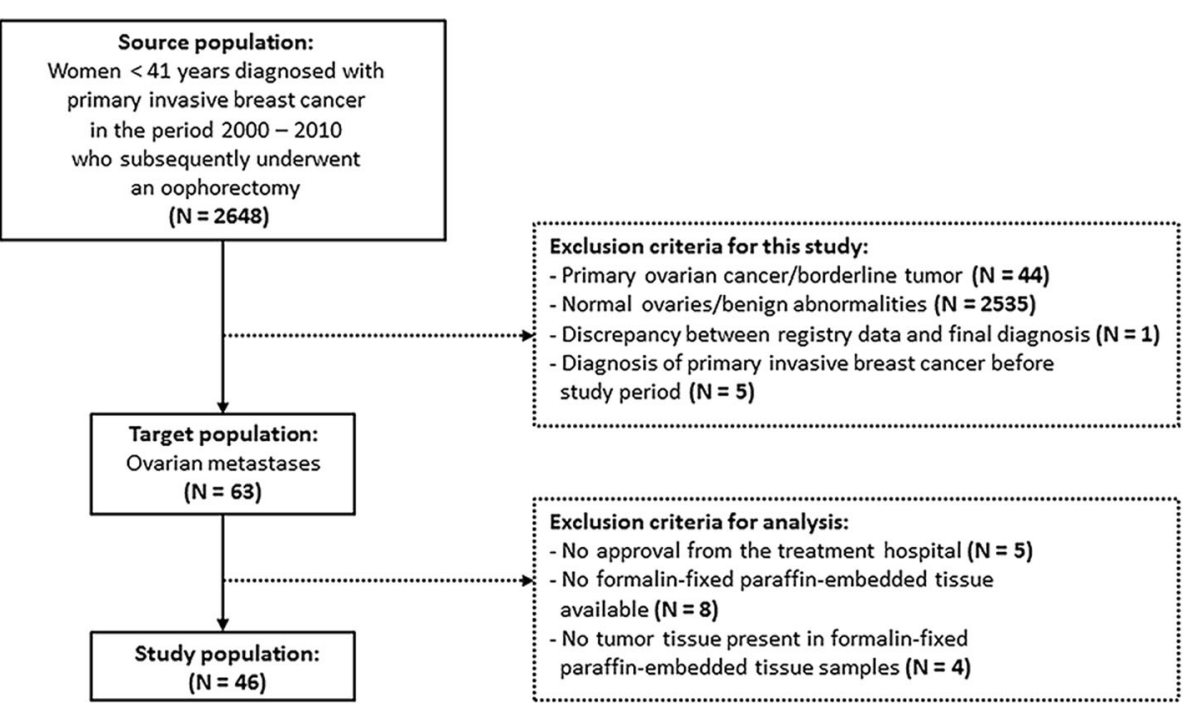

Fig. 1 Patient selection and composition of the study population. The source population was compiled by the Dutch histopathology and cytopathology network. The exclusion criteria are indicated in the dotted boxes

\section{Expression of cell-surface proteins}

Immunohistochemistry was performed to determine which cell-surface proteins are suitable as a target for tumorspecific imaging of ovarian metastases from invasive breast cancer. A strong correlation was observed between the scoring results obtained by the two observers; the median $R^{2}$ was 0.846 (range: 0.640-0.960). Representative examples of the immunohistochemical stainings of the invasive breast tumor samples and their corresponding ovarian metastases are shown in Additional file 1: Figure S1.

Table 3 shows the mean percentage of positive tumor cells for the investigated markers in primary and recurrent invasive breast tumors and their ovarian metastases. Since loss of expression of the cell-adhesion molecule Ecadherin frequently occurs in invasive lobular carcinomas [25], the expression of markers was examined by histological subtype. With respect to invasive ductal carcinomas, E-cadherin, EMA and Her2/neu were most suitable; these markers were present in 91,84 and $81 \%$ of metastatic breast tumor cells in the ovaries, respectively. In invasive lobular carcinomas, the mean percentage of positively stained breast tumor cells in the ovaries was highest for EMA, Her2/neu and EpCAM; specifically, 64, 74 and $68 \%$, respectively. In patients diagnosed with ductolobular breast cancer, targeting EMA would result in the detection of $99 \%$ of disseminated breast cancer cells in the ovaries.

\section{Correlation between the expression of cell-surface proteins in invasive breast tumors and their corresponding ovarian metastases}

In patients diagnosed with ductolobular breast cancer, the expression of EMA in the invasive breast tumors was in accordance with the expression in their corresponding ovarian metastases, showing small standard deviations (Table 3). Therefore, EMA would be the most suitable target to detect ductolobular ovarian metastases. By contrast, in patients diagnosed with ductal or lobular breast cancer large variations in expression among tumors were found. To understand whether in these patients invasive breast tumor tissues can be used to predict the most suitable target for the detection of ovarian metastases in an individual patient, scatter plots were made (Fig. 3). For each patient, the percentage of positive tumor cells in primary and locally recurrent breast tumors (if applicable) was set against the percentage of positive tumor cells in their corresponding ovarian metastases. No correlation between these expressions could be substantiated, showing that ductal and lobular breast tumor tissues cannot be used to predict the most pertinent marker for the detection of their corresponding ovarian metastases.

\section{Detection of ovarian metastases by a combination of markers}

Figure 3 also shows that the use of one marker would not always be sufficient to detect all metastatic ductal or lobular breast cancer cells in the ovaries. The use of one marker (E-cadherin, EMA or Her2/neu) would result in the detection of $100 \%$ of tumor cells in 44 out of 58 ductal ovarian metastases (data not shown). With respect to the lobular subtype, EMA, Her2/neu or EpCAM was present in $100 \%$ of tumor cells in 4 out of 10 ovarian metastases. To investigate whether a combination of markers would enable the detection of $100 \%$ of tumor cells in all ductal and lobular ovarian metastases, an 
Table 1 Clinicopathological characteristics of patients with primary invasive breast cancer and ovarian metastases

\begin{tabular}{lll}
\hline Clinicopathological characteristics & $N=46$ & $\%$ \\
\hline Age at diagnosis of breast cancer, & $36.5(28-40)$ & -
\end{tabular}
years - median (range)

$B R C A$ gene mutation

No
Yes, BRCA 1
Yes, BRCA 2
Unknown

Breast tumor localization

Left
Right
Both

Most extensively performed breast surgery

Needle biopsy

Breast conserving surgery

Mastectomy

Breast tumor histological subtype

$\begin{array}{ll}\text { Ductal } & 36 \\ \text { Lobular } & 5 \\ \text { Ductolobular } & 5 \\ \text { Scarff-Bloom-Richardson grade } & \end{array}$

Scarff-Bloom-Richardson grade

।
III
Unknown

Estrogen receptor

$\begin{array}{ll}\text { Negative } & 5 \\ \text { Positive } & 4\end{array}$

Progesterone receptor

$\begin{array}{ll}\text { Negative } & 8 \\ \text { Positive } & 38 \\ \text { Her2/neu receptor } & \end{array}$

Negative
Positive

Tumor stage

$\begin{array}{ll}\text { T1 } & 1 \\ \text { T2 } & 24 \\ \text { T3 } & 7 \\ \text { T4 } & 4 \\ \text { Nodal stage } & \end{array}$

$\begin{array}{ll}\text { N0 } & 14 \\ \text { N1 } & 12 \\ \text { N2 } & 10 \\ \text { N3 } & 10\end{array}$

\section{8}

17.4

0.0

50.0

45.7

5

5

4

\section{7}

41.3

32.6

17.4

10.9

89.1

17.4

82.6

82.6

17.4

23.9

52.2

15.2

15.2

8.7

30.4

26.1

21.7

21.7
Table 1 Clinicopathological characteristics of patients with primary invasive breast cancer and ovarian metastases (Continued)

\begin{tabular}{|c|c|c|}
\hline \multicolumn{3}{|l|}{ Distant metastasis } \\
\hline cMO & 39 & 84.8 \\
\hline cM1 & 7 & 15.2 \\
\hline $\begin{array}{l}\text { Age at diagnosis of ovarian metastases, } \\
\text { years - median (range) }\end{array}$ & $40.0(31-51)$ & - \\
\hline $\begin{array}{l}\text { Time between breast cancer and ovarian } \\
\text { metastases, months - median (range) }\end{array}$ & $41.9(0.3-141.8)$ & - \\
\hline \multicolumn{3}{|l|}{ Recurrent disease prior to oophorectomy } \\
\hline No & 15 & 32.6 \\
\hline Yes, locoregional recurrence & 12 & 26.1 \\
\hline Yes, distant recurrence & 19 & 41.3 \\
\hline \multicolumn{3}{|l|}{ Type of ovarian surgery } \\
\hline Unilateral oophorectomy & 0 & 0.0 \\
\hline Bilateral oophorectomy & 46 & 100.0 \\
\hline \multicolumn{3}{|l|}{ Indication for oophorectomy } \\
\hline Prophylactic because of breast cancer & 9 & 19.6 \\
\hline Therapeutic because of breast cancer & 25 & 54.3 \\
\hline Abnormal ovaries on ultrasound & 12 & 26.1 \\
\hline \multicolumn{3}{|l|}{ Localization of ovarian metastases } \\
\hline Left & 4 & 8.7 \\
\hline Right & 6 & 13.0 \\
\hline Both & 29 & 63.0 \\
\hline Unknown & 7 & 15.2 \\
\hline
\end{tabular}

Table 2 Localization and morphology of ovarian metastases derived from patients diagnosed with invasive breast cancer

\begin{tabular}{lll}
\hline Histological features & \multicolumn{2}{l}{ Ovarian metastases } \\
\cline { 2 - 3 } & $N=75$ & $\%$ \\
\hline Localization of ovarian metastases & & \\
Cortex & 14 & 18.7 \\
Medulla & 8 & 10.7 \\
Both & 53 & 70.1 \\
Morphology of ovarian metastases & & \\
Solitary metastasis & 15 & 20.0 \\
Multiple distinct nodules separated & 38 & 50.7 \\
by uninvolved ovarian tissue & & \\
Diffuse seeding without any discernable pattern & 22 & 29.3 \\
Fallopian tube involved & & \\
No & 55 & 73.3 \\
Yes & 5 & 6.7 \\
Unknown & 15 & 20.0 \\
\hline
\end{tabular}

Of the 46 patients who were diagnosed with invasive breast cancer and ovarian metastases, 29 patients had metastases in both ovaries. The total number of ovaries that contained metastases was 75 

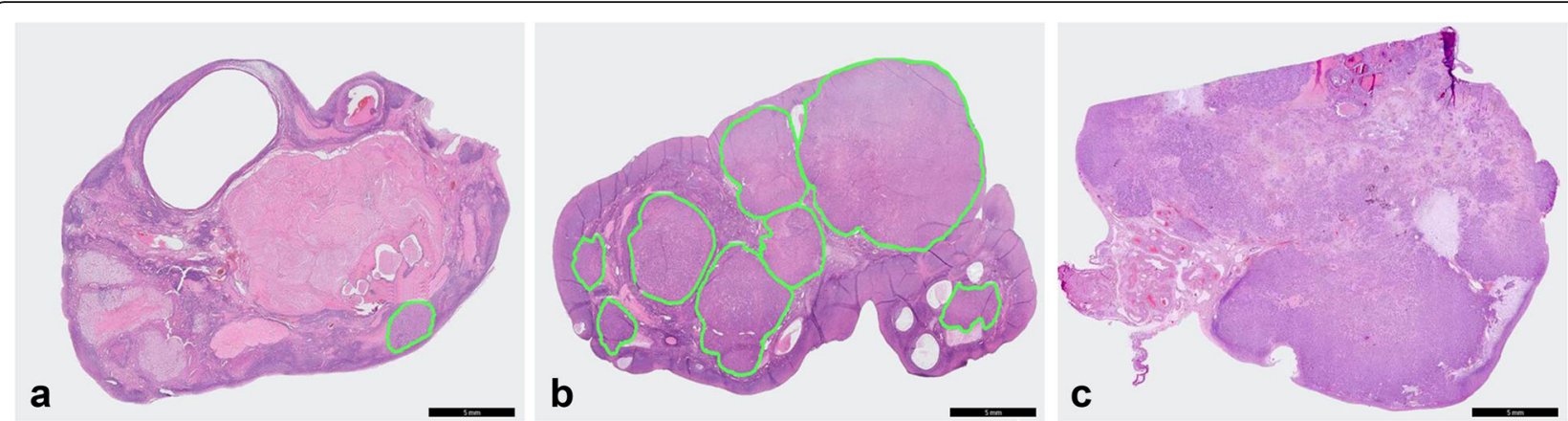

Fig. 2 Localization of ovarian metastases derived from patients diagnosed with invasive breast cancer. Three examples are shown: (a) a solitary metastasis, (b) multiple distinct nodules separated by uninvolved ovarian tissue and (c) diffuse seeding without any discernable pattern. In order to clearly display the solitary metastasis in (a) and the multiple distinct nodules in (b), a green line is drawn that delineates the metastases in the ovary. Scale bars represent $5 \mathrm{~mm}$

immunofluorescent triple staining was performed. By combining the three most suitable markers for the ductal (E-cadherin, EMA and Her2/neu) and lobular (EMA, Her2/neu and EpCAM) subtypes, 100\% tumor cell detection was accomplished in 53 out of 58 ductal ovarian metastases and in 7 out of 10 lobular ovarian metastases. Hence, cells within ovarian tissues that show membranous positivity for any of the three markers mentioned will be deemed malignant. In the remaining five ductal and three lobular ovarian metastases, the mean percentage of undetected metastatic cells was 5\% (no range) and 25\% (range 10-40), respectively. Figure 4 shows a representative image of the immunofluorescent triple staining in a lobular ovarian metastasis, in which the combination of EpCAM, EMA and Her2/neu led to the detection of all metastatic breast cancer cells.

\section{Discussion}

One of the purposes of the present study was to examine the histological features of ovarian metastases in breast cancer patients to evaluate the current tumor detection approach [4] in ovarian tissues considered for autotransplantation. We found that $71 \%$ of ovarian metastases consisted of a solitary metastasis or multiple distinct nodules separated by uninvolved ovarian tissue. These findings suggest that tumor cells might have been missed if the current tumor detection approach would have been used. The patients included in this study however, underwent oophorectomy after a median time interval of 42 months. In patients undergoing ovarian tissue cryopreservation an oophorectomy is performed soon after cancer diagnosis. In these patients, disseminated tumor cells may not yet have outgrown into overt metastases and may appear as micrometastases in the ovarian tissues [23, 26, 27]. The chance that tumor cells will then be overlooked is presumably greater. We therefore recommend examination of the actual ovarian autografts on the presence of malignant cells prior to autotransplantation.

Table 3 Immunohistochemical expression of the investigated markers in invasive breast tumors and their corresponding ovarian metastases

\begin{tabular}{|c|c|c|c|c|c|c|c|c|c|c|c|c|}
\hline \multirow[t]{3}{*}{ Marker } & \multicolumn{4}{|c|}{$\begin{array}{l}\% \text { of positive tumor cells in } \\
\text { invasive ductal carcinoma }\end{array}$} & \multicolumn{4}{|c|}{$\begin{array}{l}\% \text { of positive tumor cells in } \\
\text { invasive lobular carcinoma }\end{array}$} & \multicolumn{4}{|c|}{$\begin{array}{l}\% \text { of positive tumor cells in } \\
\text { invasive ductolobular carcinoma }\end{array}$} \\
\hline & \multicolumn{2}{|c|}{$\begin{array}{l}\text { Breast tumors } \\
(n=44)\end{array}$} & \multicolumn{2}{|c|}{$\begin{array}{l}\text { Ovarian metastases } \\
(n=58)\end{array}$} & \multicolumn{2}{|c|}{$\begin{array}{l}\text { Breast tumors } \\
(n=7)\end{array}$} & \multicolumn{2}{|c|}{$\begin{array}{l}\text { Ovarian metastases } \\
(n=10)\end{array}$} & \multicolumn{2}{|c|}{ Breast tumors $(n=7)$} & \multicolumn{2}{|c|}{$\begin{array}{l}\text { Ovarian metastases } \\
(n=7)\end{array}$} \\
\hline & Mean & SD & Mean & $S D$ & Mean & $S D$ & Mean & $S D$ & Mean & $S D$ & Mean & $S D$ \\
\hline E-cadherin & 91 & 18 & 91 & 20 & 9 & 23 & 0 & 0 & 73 & 35 & 51 & 41 \\
\hline EMA & 86 & 23 & 84 & 24 & 86 & 32 & 64 & 32 & 97 & 6 & 99 & 2 \\
\hline Her2/neu & 76 & 35 & 81 & 31 & 88 & 26 & 74 & 26 & 80 & 34 & 67 & 38 \\
\hline CEA & 56 & 40 & 57 & 39 & 73 & 32 & 59 & 26 & 62 & 32 & 56 & 33 \\
\hline av $\beta 6$ integrin & 51 & 40 & 45 & 39 & 54 & 35 & 38 & 28 & 45 & 30 & 29 & 35 \\
\hline EpCAM & 36 & 42 & 38 & 39 & 38 & 46 & 68 & 26 & 19 & 29 & 35 & 29 \\
\hline $\mathrm{SD}=$ standard deviation & & & & & & & & & & & & \\
\hline
\end{tabular}

The mean percentages of immunohistochemically positive stained tumor cells are subdivided by histological subtype. Tumor cell membranes were considered positive if they showed immunoreactivity of any intensity. EMA, epithelial membrane antigen; Her2/neu, human epidermal growth receptor type 2; CEA, carcinoembryonic antigen; EpCAM, epithelial cell adhesion molecule 


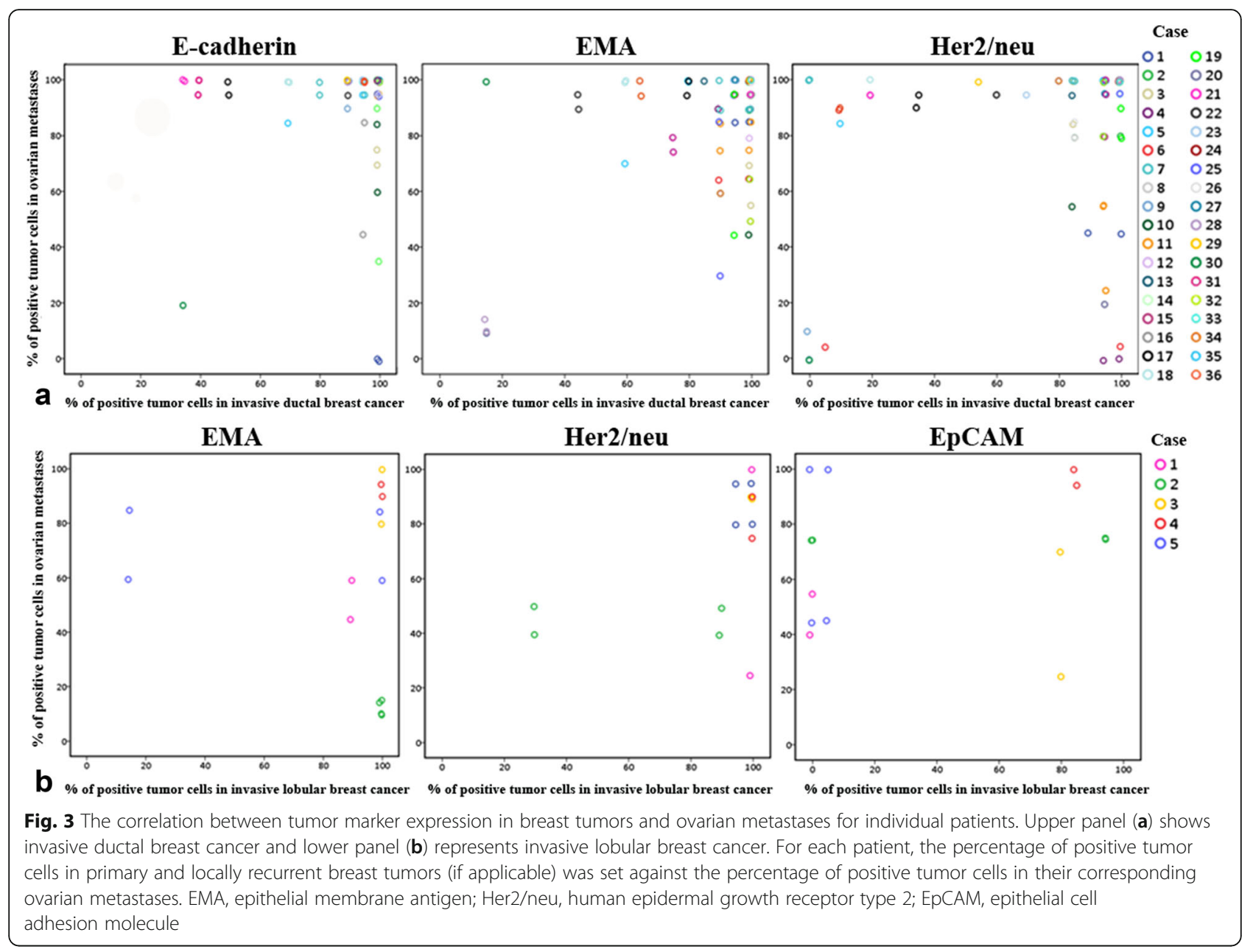

In our study, merely 63 out of 2648 patients (2.4\%) who were diagnosed with primary invasive breast cancer at age $<41$ years had ovarian metastases. For the determination of suitable targets for NIRF imaging, it might have been relevant to focus on malignancies with a higher risk of ovarian contamination in the actual patient population, for instance leukemia [28-30]. Nonetheless, breast cancer can be perfectly used as a starting point to investigate whether NIRF imaging is feasible for the detection of ovarian metastases.

Considering the expression of Her2/neu in primary invasive breast cancers and ovarian metastases a high percentage of Her2/neu positive tumor cells (67-88\%) was found, as we considered tumor cell membranes positive if they showed immunoreactivity of any intensity. This is in contrast to the diagnostic setting, where Her2/neu overexpression is determined because of its potential prognostic value $[17,31]$. We applied a lower cut-off point, because for NIRF imaging the staining intensity is less important as long as a significant tumor-to-background-ratio can be achieved. In the NIR spectrum, non-specific fluorescence background signal is substantially decreased compared to wavelengths lower than NIR [8]. Hence, since ovarian stromal cells do not immunohistochemically express Her2/neu [32], Her2/neu-targeting NIRF probes will detect metastatic breast cancer cells within ovarian tissues if these cells show immunohistochemical reactivity.

In individual patients, no correlation was found between the expression of the investigated markers in breast tumors and their corresponding metastases in the ovary. This might be due to the fact that breast cancer is known as a heterogeneous disease [17] or be in line with the hypothesis that disseminated tumor cells autonomously evolve from the primary tumor [33]. For the clinical application of these markers there should not be an obstacle, since a combination of three markers enhances the ability to detect breast tumor cells in ductal and lobular ovarian metastases. Furthermore, only the histological subtype of the invasive breast tumor needs to be known to determine which combination of markers is pertinent for the detection of the corresponding ovarian metastases, making the selection of suitable NIRF probes simple and straightforward. For the non- 

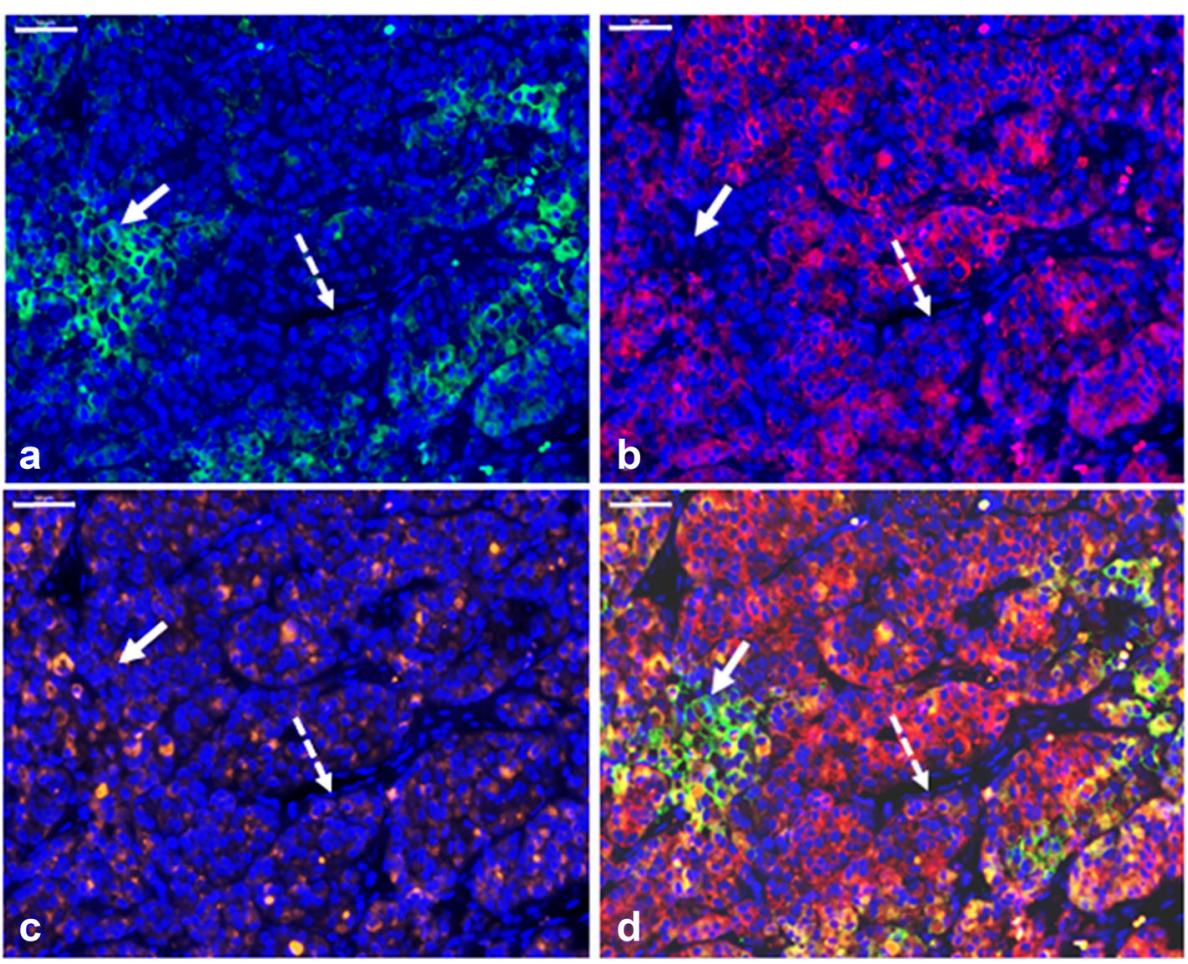

Fig. 4 Detection of ovarian metastases by a combination of markers. Representative image of a lobular ovarian metastasis stained with DAPI counterstain and triple immunofluorescence for $\operatorname{EpCAM}(\mathbf{a})$, EMA (b), Her2/neu (c), and the three stainings combined (d). The solid arrow indicates tumor cells that are positive for EpCAM, but negative for EMA and Her2/neu. The dashed arrow indicates tumor cells that are positive for Her2/neu, but negative for EpCAM and EMA. Scale bars represent $100 \mu \mathrm{m}$. EpCAM, epithelial cell adhesion molecule; EMA, epithelial membrane antigen; Her2/neu, human epidermal growth receptor type 2

invasive detection of metastases in the actual ovarian autografts by tumor-specific imaging, NIRF probes could be administered intravenously, after which the removed ovary is dissected into cortical ovarian strips. Subcellular detailed fluorescent images of tumor cells within ovarian autografts could then be obtained by multiphoton microscopy [34]. Beside breast cancer cells, inclusion cysts will likely also be illuminated by NIRF imaging, as we previously showed that in normal ovaries, all markers (except CEA) were expressed on epithelial cells in inclusion cysts [32]. Nevertheless, we additionally demonstrated that full-field optical coherence tomography (FF-OCT), which creates histology-like images without the need for tissue manipulation, can be perfectly used to differentiate between inclusion cysts and metastases in the ovary [35]. On a tomographic FF-OCT image, an inclusion cyst is characterized by a thin dark outer layer and lack of interior structure, whereas micrometastatic lesions from primary invasive ductal carcinomas present as 'web-like' structures in which tumor cells appear light gray. Metastatic lesions derived from primary invasive lobular carcinomas often show an Indian file pattern, defined as infiltrating single rows of cells [36]. Since ovarian inclusion cysts are separately identifiable within the ovarian parenchyma [32], a distinction between these structures can also be made. In addition, FF-OCT and NIRF imaging might be combined to enhance their sensitivity and specificity rates, as both methods are noninvasive. The a priori probability that other benign epithelial ovarian abnormalities will be detected by our panel of cell-surface markers is low, since ovaries that present as an adnexal mass on preoperative ultrasonography are generally not used for ovarian tissue cryopreservation. In case primary ovarian cancer cells are present, these cells will be detected as E-cadherin [37], EMA [38], and EpCAM [39] are virtually always expressed in ovarian cancer, and approximately $33 \%$ of primary ovarian carcinomas show Her2/neu amplification [40].

\section{Conclusions}

In conclusion, we showed that in young breast cancer patients with ovarian metastases, metastatic breast tumor cells may be confined to a specific area in the ovarian cortex. A non-invasive tumor detection technique by which cortical ovarian fragments that are transplanted can be examined, is recommended to minimize the risk of reintroducing metastatic tumor cells by 
ovarian tissue autotransplantation in breast cancer patients. NIRF imaging is a promising technique to discriminate malignant from benign tissues while leaving the examined tissues vital. Our research opens a new avenue for the development of tumor-specific NIRF probes that can be used for non-invasive detection of breast cancer metastases in ovarian tissues prior to autotransplantation.

\section{Additional files}

Additional file 1: Figure S1. Immunohistochemical expression of tumor markers in invasive breast tumors and their corresponding ovarian metastases. Arrows indicate tumor cells that show heterogeneous expression of markers. Scale bars represent 100 um. EMA, epithelia membrane antigen; Her2/neu, human epidermal growth receptor type 2; CEA, carcinoembryonic antigen; EpCAM, epithelial cell adhesion molecule. (TIFF $5316 \mathrm{~kb}$ )

Additional file 2: Table S2. List of participating hospitals. An overview is given of the treatment hospitals that approved the study design. (DOCX $14 \mathrm{~kb}$ )

\section{Author details}

${ }^{1}$ Department of Gynecology, Leiden University Medical Center, Leiden, the Netherlands. '2Department of Surgery, Leiden University Medical Center, Leiden, the Netherlands. ${ }^{3}$ Department of Gynecology, Reinier de Graaf Hospital, Delft, the Netherlands. ${ }^{4}$ Department of Pathology, Leiden University Medical Center, Leiden, the Netherlands.

Received: 23 December 2016 Accepted: 11 March 2017

Published online: 21 March 2017

\section{Abbreviations}

ASRM: American Society for Reproductive Medicine; CEA: Carcinoembryonic antigen; CK-7: Cytokeratin 7; DAB: Diaminobenzidine; DAPI: 4',6-diamidino-2 phenylindole; EMA: Epithelial membrane antigen; EpCAM: Epithelial cell adhesion molecule; FFPE: Formalin-fixed paraffin-embedded; FMWV: Dutch Federation of Biomedical Scientific Societies; GCDFP15: Gross cystic disease fluid protein-15; H\&E: Hematoxylin-and-eosin; Her2/neu: Human epidermal growth receptor type 2; NIRF: Near-infrared fluorescence; PALGA: the Dutch Pathology Registry; PBS: Phosphate buffered saline; PCR: Polymerase chain reaction; pH: Potential hydrogen; PT: Pre-treatment; SPSS: Statistical package for the social sciences; WT1: Wilms' tumor antigen-1

\section{Acknowledgments}

The authors gratefully acknowledge the Dutch Pathology Registry (PALGA) the pathology laboratories, and the treatment hospitals for their collaboration. The authors also thank Rob Keyzer, BSc, Ronald L.P. van Vlierberghe, BSc for practical help, and Erik W. van Zwet, PhD for assistance with statistical analysis. These contributors have no conflict of interest.

\section{Funding}

This work was supported by the project grant H2020-MSCA-RISE grant number 644373 - PRISAR, DSW Health Insurance and the Zabawas Foundation. These funding sources were not involved in any part of the study.

\section{Availability of data and material}

The datasets used during the current study are available from the corresponding author on reasonable request.

\section{Authors' contributions}

$I P, C H, V S, A L, C S, J B T, P K$ designed the study. IP, MS, BH, CS, PK performed experiments and/or gave technical support. IP analyzed data and prepared figures. IP wrote the manuscript. All authors read and approved the final manuscript, and agreed to be accountable for all aspects of the work.

\section{Competing interests}

The authors declare that they have no competing interests.

\section{Consent for publication}

Not applicable.

\section{Ethics approval and consent to participate}

This study was approved by the medical ethical committee of the Leiden University Medical Center (protocol number P14.106) and the local medical ethical committees of the participating hospitals (Additional file 2: Table S2). Written human subject consent was not necessary, as the processing of personal data was performed according with the Wbp (Personal Data Protection Act). We received permission from the Dutch Pathology Registry (PALGA) to access the PALGA dataset. All patient samples and clinical data were handled in accordance with the medical ethics guidelines described in the Code of Conduct for Proper Secondary Use of Human Tissue of the Dutch Federation of Biomedical Scientific Societies (FMWV) [41].

\section{Publisher's Note}

Springer Nature remains neutral with regard to jurisdictional claims in published maps and institutional affiliations.

\section{References}

1. Donnez J, Dolmans MM. Ovarian tissue freezing: current status. Curr Opin Obstet Gynecol. 2015;27(3):222-30.

2. Jensen AK, Macklon KT, Fedder J, Ernst E, Humaidan P, Andersen CY. 86 succesful births and 9 ongoing pregnancies worldwide in women transplanted with frozen-thawed ovarian tissue: focus on birth and perinatal outcome in 40 of these children. J Assist Reprod Genet. 2016; doi:10.1007/s10815-016-0843-9.

3. The Practice Committee of the American Society for Reproductive Medicine Ovarian tissue cryopreservation: a committee opinion. Fertil Steril. 2014; 101(5):1237-43.

4. Bastings $L$, Beerendonk CCM, Westphal JR, Braat DDM, Peek R. Cryopreservation and Autotransplantation of Ovarian Tissue in Cancer Patients: Is It Safe? J Adolesc Young Adult Oncol. 2013;2(1):31-4.

5. Bittinger SE, Nazaretian SP, Gook DA, Parmar C, Harrup RA, Stern CJ. Detection of Hodgkin lymphoma within ovarian tissue. Fertil Steril. 2011;95(2):803.e803-6.

6. Rosendahl M, Timmermans Wielenga $\mathrm{V}$, Nedergaard L, et al. Cryopreservation of ovarian tissue for fertility preservation: no evidence of malignant cell contamination in ovarian tissue from patients with breast cancer. Fertil Steril. 2011;95(6):2158-61.

7. Vahrmeijer AL, Hutteman M, van der Vorst JR, et al. Image-guided cancer surgery using near-infrared fluorescence. Nat Rev. Clin Oncol. 2013;10(9):507-18.

8. Keereweer S, Kerrebijn JDF, van Driel PBAA, et al. Optical image-guided surgery-where do we stand? Mol Imaging Biol. 2011;13(2):199-207.

9. Te Velde EA, Veerman T, Subramaniam V, Ruers T. The use of fluorescent dyes and probes in surgical oncology. Eur J Surg Oncol. 2010;36(1):6-15.

10. Rosendahl M, Schmidt KT, Ernst E, et al. Cryopreservation of ovarian tissue for a decade in Denmark: a view of the technique. Reprod BioMed Online. 2011;22(2):162-71.

11. Dolmans M-M, Jadoul $P$, Gilliaux $S$, et al. A review of 15 years of ovarian tissue bank activities. J Assist Reprod Genet. 2013;30(3):305-14.

12. Oktay K, Oktem O. Ovarian cryopreservation and transplantation for fertility preservation for medical indications: report of an ongoing experience. Fertil Steril. 2010;93(3):762-8.

13. Cowin P, Rowlands TM, Hatsell SJ. Cadherins and catenins in breast cancer. Curr Opin Cell Biol. 2005;17(5):499-508.

14. Tornos C, Soslow R, Chen S, et al. Expression of WT1, CA 125 and GCFFP-15 as useful markers in the Differential Diagnosis of Primary Ovarian Carcinomas Versus Metastatic Breast Cancer to the Ovary. Am J Surg Pathol. 2005;29:1482-9

15. Luyckx V, Durant JF, Camboni A, et al. Is transplantation of cryopreserved ovarian tissue from patients with advanced-stage breast cancer safe? A pilot study. J Assist Reprod Genet. 2013;30(10):1289-99.

16. Slamon DJ, Clark GM, Wong SG, Levin WJ, Ullrich A, McGuire WL. Human breast cancer: correlation of relapse and survival with amplification of the HER-2/neu oncogene. Science. 1987;235:177-82.

17. Weigelt B, Peterse JL. van 't Veer LJ. Breast cancer metastasis: markers and models. Nat Rev. Cancer. 2005:5(8):591-602.

18. Kuhajda FP, Offutt LE, Mendelsohn G. The distribution of carcinoembryonic antigen in breast carcinoma. Diagnostic and prognostic implications. Cancer. 1983;52(7):1257-64 
19. Rathinam R, Alahari SK. Important role of integrins in the cancer biology. Cancer Metastasis Rev. 2010;29(1):223-37.

20. Schnell U, Cirulli V, Giepmans BNG. EpCAM: structure and function in health and disease. Biochim Biophys Acta. 2013;1828(8):1989-2001.

21. Soysal SD, Muenst S, Barbie T, et al. EpCAM expression varies significantly and is differentially associated with prognosis in the luminal B HER2(+), basal-like, and HER2 intrinsic subtypes of breast cancer. Br J Cancer. 2013;108(7):1480-7.

22. Van Driel PB, Boonstra MC, Prevoo HA, et al. EpCAM as multi-tumour target for near-infrared fluorescent guided surgery. BMC Cancer. 2016;16(1):884.

23. Sánchez-Serrano M, Novella-Maestre E, Roselló-Sastre E, Camarasa N, Teruel J, Pellicer A. Malignant cells are not found in ovarian cortex from breast cancer patients undergoing ovarian cortex cryopreservation. Hum Reprod. 2009;24(9):2238-43.

24. Casparie M, Tiebosch AT, Burger G, et al. Pathology databanking and biobanking in The Netherlands, a central role for PALGA, the nationwide histopathology and cytopathology data network and archive. Cell Oncol. 2007;29(1):19-24

25. Ferlicot S, Vincent-Salomon A, Medioni J, et al. Wide metastatic spreading in infiltrating lobular carcinoma of the breast. Eur J Cancer. 2004:40(3):336-41.

26. Hoekman EJ, Smit VT, Fleming TP, Louwe LA, Fleuren GJ, Hilders CG. Searching for metastases in ovarian tissue before autotransplantation: a tailor-made approach. Fertil Steril. 2014;103(2):469-77.

27. Bockstaele L, Boulenouar S, Van Den Steen G, et al. Evaluation of quantitative polymerase chain reaction markers for the detection of breast cancer cells in ovarian tissue stored for fertility preservation. Fertil Steril. 2015;104(2):410-417.e414.

28. Dolmans M-M, Marinescu C, Saussoy P, Van Langendonckt A, Amorim C, Donnez J. Reimplantation of cryopreserved ovarian tissue from patients with acute lymphoblastic leukemia is potentially unsafe. Blood. 2010;116(16):2908-14.

29. Bastings L, Beerendonk CCM, Westphal JR, et al. Autotransplantation of cryopreserved ovarian tissue in cancer survivors and the risk of reintroducing malignancy: a systematic review. Hum Reprod Update. 2013; 19(5):483-506.

30. Dolmans M-M, Luyckx V, Donnez J, Andersen CY, Greve T. Risk of transferring malignant cells with transplanted frozen-thawed ovarian tissue. Fertil Steril. 2013;99(6):1514-22.

31. Ridolfi RL, Jamehdor MR, Arber JM. HER-2/neu testing in breast carcinoma: a combined immunohistochemical and fluorescence in situ hybridization approach. Mod Pathol. 2000;13(8):866-73.

32. Peters IT, Hilders CG, Sier CF, et al. Identification of cell-surface markers for detecting breast cancer cells in ovarian tissue. Arch Gynecol Obstet. 2016;294(2):385-93.

33. Pantel K, Brakenhoff RH. Dissecting the metastatic cascade. Nat Rev. Cancer. 2004;4(6):448-56.

34. Andresen V, Alexander S, Heupel W-M, Hirschberg M, Hoffman RM, Friedl P. Infrared multiphoton microscopy: subcellular-resolved deep tissue imaging. Curr Opin Biotechnol. 2009;20(1):54-62.

35. Peters IT, Stegehuis PL, Peek R, et al. Non-invasive detection of metastases and follicle density in ovarian tissue using full-field optical coherence tomography. Clin Cancer Res. 2016; doi:10.1158/1078-0432.

36. Gagnon YTB. Ovarain metastases in breast carcinoma. Cancer. 1989;64:892-8.

37. Sundfeldt $\mathrm{K}$, Pionkewitz $Y$, Ivarsson $\mathrm{K}$, et al. E-cadherin expression in human epithelial ovarian cancer and normal ovary. Int J Cancer. 1997;74:275-80

38. Hammond RH, Bates TD, Clarke DG, et al. The immunoperoxidase localization of tumour markers in ovarian cancer: the value of CEA, EMA, cytokeratin and DD9. BJOG. 1991;98:73-83.

39. Ang WX, Li Z, Chi Z, et al. Intraperitoneal immunotherapy with T cells stably and transiently expressing anti-EpCAM CAR in xenograft models of peritoneal carcinomatosis. Oncotarget 2017; doi:10.18632/oncotarget.14592.

40. Chang KL, Lee M-Y, Chao W-R, Han C-P. The status of Her2 amplification and Kras mutations in mucinous ovarian carcinoma. Hum Genomics. 2016;10(1):40.

41. Federa FMWV. Code for proper secondary use of human tissue in the Netherlands. 2002; http://www.federa.org/codes-conduct.

\section{Submit your next manuscript to BioMed Central and we will help you at every step:}

- We accept pre-submission inquiries

- Our selector tool helps you to find the most relevant journal

- We provide round the clock customer support

- Convenient online submission

- Thorough peer review

- Inclusion in PubMed and all major indexing services

- Maximum visibility for your research

Submit your manuscript at www.biomedcentral.com/submit
Biomed Central 